\title{
Ocular Melanoma Recurrence Presenting as Cholestatic Jaundice due to Periampullary Area Metastases
}

A 76-year-old woman presented with complaints of pruritus and painless jaundice. She had undergone radical resection of a stage IIB retinal melanoma followed by chemotherapy and immunotherapy 5 years before and is free of disease in last 3 years.

On admission, she had a total bilirubin level of $9.6 \mathrm{mg} / \mathrm{dL}$ (direct, $6.3 \mathrm{mg} / \mathrm{dL}$ ) and highly elevated cholestatic enzymes. An abdominal computed tomography revealed dilation of the intrahepatic and extrahepatic biliary systems, as well as the main pancreatic duct up to the level of the major papilla. No evidence of metastases to the liver or other organs were observed. An endoscopic retrograde cholangiopancreatography image demonstrated a swollen major papilla with a blackish hue at the periampullary area and a black volcano-like lesion near the major papilla (Fig. 1). Conventional cannulation of the common bile duct was impossible. Therefore, a suprapapillary sphincterotomy was performed. Many biopsy specimens were taken through sphincterotomy, from the volcano-like lesion. A palliative 10-Fr, 7-cm plastic stent was placed (Fig. 1). Histological examination of the biopsies with hematoxylin-eosin staining revealed spindle-shaped cells with cytoplasmic brightness and nuclear atypia consistent with the diagnosis of melanoma (Fig. 2). Immunohistochemistry was positive for melan-A protein antigen, confirming the diagnosis of metastatic malignant melanoma (Fig. 2). An outpatient positron emission tomography scan showed numerous areas from the chest to the abdomen with hypermetabolic activity indicating neoplasia. She underwent palliative chemotherapy but died 6 months later.

Malignant melanoma is among the most threatening malignancies and a highly metastatic cancer. ${ }^{1}$ Gastrointestinal tract metastases involve mostly the small intestine and colon. ${ }^{2}$ Cholestatic jaundice due to major papilla or periampullary area metastases is rare. ${ }^{3}$

The endoscopic findings of melanomas metastases frequently comprise a black volcano-like lesion or infiltrates in the submucosa and extend for variable depths into the wall. ${ }^{4}$ Amelanotic lesions with variable appearance are rare entities., The diagnosis of malignancy is established by immunohistochemical analysis of biopsy specimens; the tumor marker S-100 protein positivity ranges from $30 \%$ to $100 \%$, melan-A protein an-

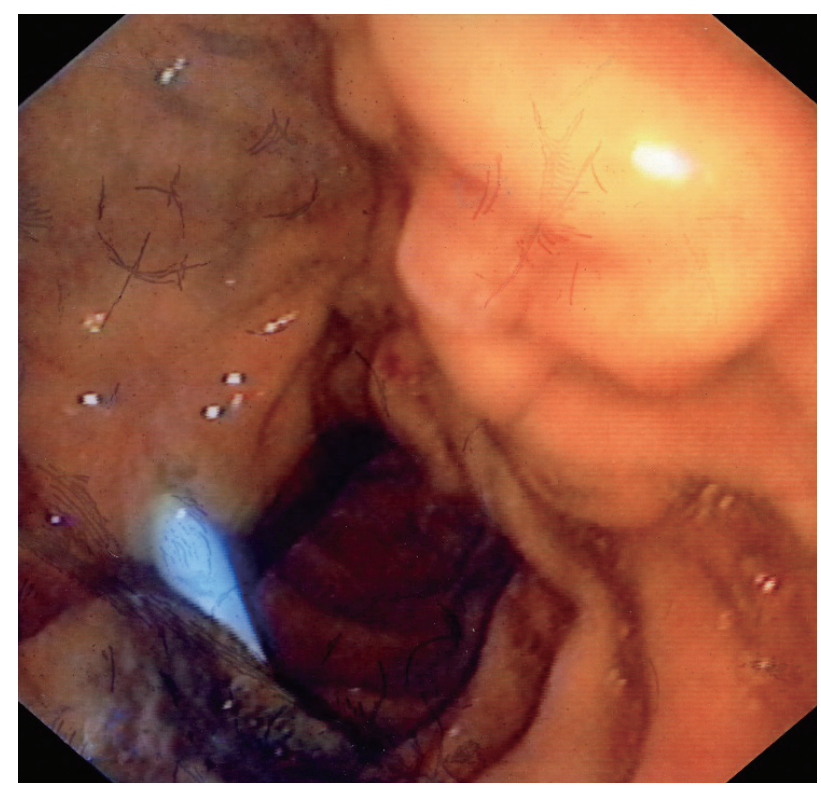

Fig. 1. Duodenoscopy image showing a periampullary area with blackish hue, a plastic stent inserted in the common bile duct, and a black volcano-like lesion near the major papilla.

Received: April 5, 2018 Revised: April 16, 2018 Accepted: April 16, 2018

Correspondence: Sotiris Anastasiadis

Section of Gastroenterology, Second Department of Internal Medicine Ippokration Hospital, Papaflessa 26a Pylaia, Thessaloniki 55534, Greece

Tel: +30-693-684-3708, Fax: +30-231-093-1345, E-mail: anassot@yahoo.gr

ORCID: https://orcid.org/0000-0003-1181-6745

cc This is an Open Access article distributed under the terms of the Creative Commons Attribution Non-Commercial License (http://creativecommons.org/licenses/bync/3.0) which permits unrestricted non-commercial use, distribution, and reproduction in any medium, provided the original work is properly cited. 

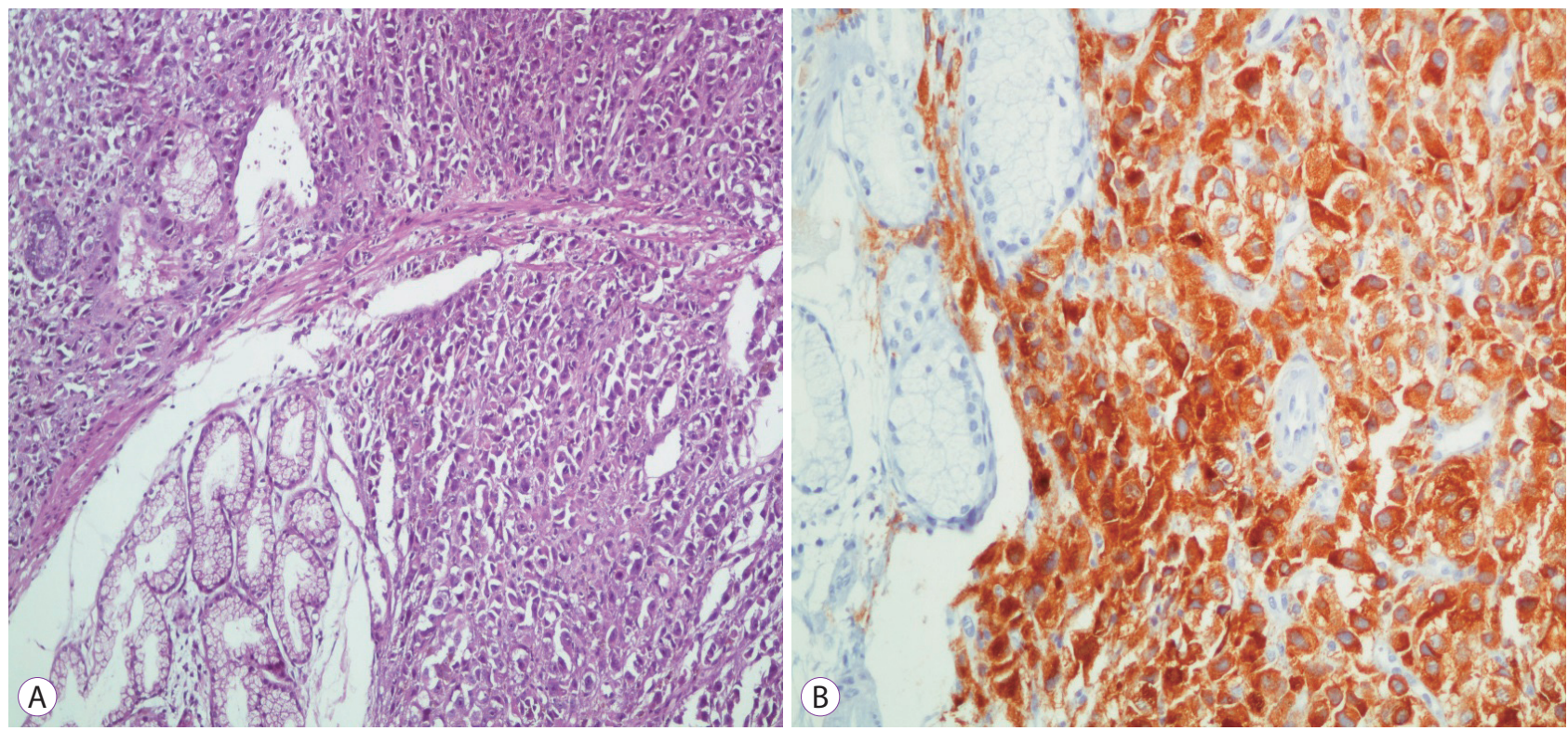

Fig. 2. (A) Stranded proliferation of spindle-shaped cells with cytoplasmic brightness and nuclear atypia (hematoxylin-eosin, original magnification $\times 200)$. (B) Immunohistochemical staining showing positivity for melan-A.

tigen has high specificity (100\%), and HMB-45 protein displays high specificity (100\%) and sensitivity of $80 \%-90 \%{ }^{1}$

\section{Conflicts of Interest}

The authors have no financial conflicts of interest.

\section{Sotiris Anastasiadis, Andreas Xanthis, Jannis Kountouras and Panagiotis Katsinelos}

Section of Gastroenterology, Second Department of Internal Medicine Ippokration Hospital, Thessaloniki, Greece

\section{REFERENCES}

1. Schuchter LM, Green R, Fraker D. Primary and metastatic diseases in malignant melanoma of the gastrointestinal tract. Curr Opin Oncol 2000;12:181-185.

2. Blecker D, Abraham S, Furth EE, Kochman ML. Melanoma in the gastrointestinal tract. Am J Gastroenterol 1999;94:3427-3433.

3. Marks JA, Rao AS, Loren D, Witkiewicz A, Mastrangelo MJ, Berger AC. Malignant melanoma presenting as obstructive jaundice secondary to metastasis to the ampulla of Vater. JOP 2010;11:173-175.

4. Kadakia SC, Parker A, Canales L. Metastatic tumors to the upper gastrointestinal tract: endoscopic experience. Am J Gastroenterol 1992;87:1418-1423. 